\title{
Commentary \\ Routine use of weaning predictors: not so fast
}

Scott K Epstein

Office of Educational Affairs, Tufts University School of Medicine, 145 Harrison Avenue, Room 317, Boston, MA 02111, USA

Corresponding author: Scott K Epstein, Scott.Epstein@tufts.edu

Published: 21 October 2009

Critical Care 2009, 13:197 (doi:10.1186/cc8121)

This article is online at http://ccforum.com/content/13/5/197

(c) 2009 BioMed Central Ltd

See related research by Nemer et al., http://ccforum.com/content/13/5/R152

\begin{abstract}
Weaning from mechanical ventilation remains a major challenge for critical care physicians. Because subjective criteria are inaccurate, objective measurements consisting of clinical criteria and physiologic tests (weaning predictors) have been used to facilitate decision-making. An integrated weaning index calculated as the product of static compliance and arterial oxygen saturation divided by the frequency-tidal volume ratio appears to be more accurate than other currently available predictors. Despite the accuracy of this new test, a beneficial effect on outcome is yet to be proven.
\end{abstract}

Invasive mechanical ventilation provides support during recovery from acute respiratory failure but results in complications, and longer duration of intubation is associated with increased mortality. Patients should therefore be weaned and extubated as soon as it is safe to do so. Objective physiologic measurements (weaning predictors) are often used as surrogate markers of recovery [1]. Unfortunately, an evidence-based review identified relatively few predictors associated with clinically significant changes in the probability of weaning success or failure [2].

Of the predictors studied, the respiratory frequency to tidal volume ratio $\left(f / V_{T}\right)$ appears to be most accurate [3]. Because weaning failure often results from a complex interplay of factors, a more comprehensive integrative index may prove superior. Milic-Emili first proposed an inspiratory effort quotient to predict unsuccessful weaning [4]:

Inspiratory effort quotient $=\left[\left(0.75 \mathrm{~V}_{\mathrm{T}} / \mathrm{C}_{\mathrm{dyn}}\right) \times\left(\mathrm{T}_{\mathrm{l}} / \mathrm{T}_{\mathrm{TOT}}\right)\right] / \mathrm{MIP}$

where $\mathrm{C}_{\text {dyn }}$ is the dynamic compliance, MIP is the maximal inspiratory pressure and $T_{1} / T_{\text {TOT }}$ is the respiratory duty cycle. Yang and Tobin developed the Compliance, Respiratory Rate, Oxygenation, and Pressure (CROP) index by incorpora- ting measurements of $\mathrm{C}_{\text {dyn }}, \mathrm{MIP}$ (pressure), $\mathrm{PaO}_{2} / \mathrm{PAO}_{2}$ (oxygenation) and the respiratory rate [3]:

$$
\begin{gathered}
\text { CROP }(\mathrm{ml} / \text { breath } / \text { minute })= \\
{\left[\mathrm{C}_{\text {dyn }} \times \mathrm{MIP} \times\left(\mathrm{PaO}_{2} / \mathrm{PAO}_{2}\right)\right] / \text { respiratory rate }}
\end{gathered}
$$

In a prospective study, a CROP of $13 \mathrm{ml} / \mathrm{breath} /$ minute yielded a positive predictive value and a negative predictive value of 0.71 and 0.70 , respectively, but was less accurate than the $f / V_{T}$. Jabour and colleagues examined a weaning index, the product of a modified pressure time index and an index of gas exchange efficiency. In a post-hoc analysis, the weaning index was highly accurate with the positive predictive value and negative predictive value approaching unity [5].

Nemer and coworkers now report a new integrative weaning index (IWI) that accurately predicts weaning outcome [1]. The IWI is calculated as the product of static compliance and arterial oxygen saturation divided by the $f / V_{T}$. Threshold values were determined in 115 patients and were prospectively validated in an additional 216 patients. Receiver operator characteristic analysis showed the IWI to be more accurate than the frequency, the tidal volume, the $f / V_{T}$, the static compliance of the respiratory system, $\mathrm{PaO}_{2} / \mathrm{FiO}_{2}$, the airway occlusion pressure, and the airway occlusion pressure $x$ $\mathrm{f} / \mathrm{V}_{\mathrm{T}}$ product. Using a threshold of $25 \mathrm{ml} / \mathrm{cmH}_{2} \mathrm{O} / \mathrm{breaths} / \mathrm{l} /$ minute gave a sensitivity of 0.97 and a specificity of 0.94 . One limitation of the study is the difficulty in measuring static compliance of the respiratory system in the spontaneously breathing patient. The authors combined spontaneous breathing trial (SBT) failure and extubation failure, an approach to be discouraged because the latter often results from distinct causes related to the capacity to protect the

$\mathrm{C}_{\mathrm{dyn}}=$ dynamic compliance; $\mathrm{CROP}=$ Compliance, Respiratory Rate, Oxygenation, and Pressure; $\mathrm{FiO}_{2}=$ fractional inspired oxygen concentration; $\mathrm{f} / \mathrm{T}=$ respiratory frequency to tidal volume ratio; IWI = integrative weaning index; MIP = maximal inspiratory pressure; $\mathrm{PaO}_{2}=$ partial pressure of arterial oxygenation; $\mathrm{PAO}_{2}=$ partial pressure of alveolar oxygen; $\mathrm{SBT}=$ spontaneous breathing trial; $\mathrm{T}_{1} / \mathrm{T}_{\mathrm{TOT}}=$ respiratory duty cycle. 
airway. Although the IWI appeared to identify 9 out of 10 extubation failures, the small number of events precludes meaningful analysis.

Two weaning consensus conferences failed to recommend routine use of weaning predictors, probably because of variable accuracy $[6,7]$. Should that recommendation change if the accuracy of the IWI can be confirmed? Weaning predictors should identify all patients ready for spontaneous breathing to avoid unnecessary prolongation of intubation. Observational studies (retrospective or prospective) cannot address this question because weaning predictors are not used to determine whether a patient undergoes a SBT - that decision is made using clinical screening criteria.

Girard and colleagues screened patients for adequate oxygenation (oxygen saturation by pulse oximetry $\geq 88 \%$ on $\mathrm{FiO}_{2} \leq 50 \%$ and positive end-expiratory pressure $\leq 8 \mathrm{cmH}_{2} \mathrm{O}$ ), hemodynamic stability, any spontaneous inspiratory effort, and the absence of agitation, myocardial ischemia and increased intracranial pressure [8]. No weaning predictors were used. Using these screening criteria, more than $50 \%$ of patients tolerated the resulting SBT and those patients failing the SBT did not suffer adverse effects.

When using this SBT approach, adding a weaning predictor will not increase the number of patients allowed to breathe spontaneously, unless the predictor trumps the other clinical criteria (for example, SBTs given despite inadequate oxygen, hemodynamic instability, agitation, or active myocardial ischemia). The reason to use a weaning predictor is therefore as a confirmatory test; a patient having a favorable result undergoes a SBT, while the patient with a negative result ( $f / V_{\mathrm{T}}>100$ breaths $/ /$ minute) is maintained on full support. In other words, the objective is to identify the patient not yet ready for spontaneous breathing, with a goal of avoiding the adverse effects of a failed SBT.

There is no evidence that a well monitored but failed SBT is harmful, however, as long as the patient is returned to full ventilatory support at the first sign of intolerance. Ely and colleagues found SBTs to be exceedingly safe even when used in a cohort of $>1,000$ patients [9]. Laghi and colleagues found that low-frequency fatigue (the type that could hinder future weaning attempts) did not occur during a failed T-piece trial [10]. Funk and colleagues found no difference in mortality between patients passing their first SBT (followed by successful extubation) and those failing their first SBT (and requiring up to three SBTs before successful extubation) [11].

We conducted the only published randomized controlled trial where weaning decision-making hinged solely on a weaning predictor measurement [12]. All patients underwent a fivecomponent daily screen, including $\mathrm{PaO}_{2} / \mathrm{FiO}_{2}$, positive endexpiratory pressure, hemodynamic stability, mental status, adequate cough and $f / V_{T}$. Those patients passing the screen automatically underwent a 2-hour SBT and were considered for extubation if the SBT was tolerated. Based on randomization, in one group the $f / V_{T}$ was not used for weaning decisionmaking while in the other group only patients with $f / V_{T}$ $<105$ breaths $/ / /$ minute underwent a SBT. The group randomized to use of the $f / V_{T}$ took longer to wean from the ventilator, other outcome measures being similar.

In summary, there is no shortage of observational investigations examining the accuracy of weaning predictors. Whether accurate or not, there is no high-level evidence demonstrating that routine application of weaning predictors improves outcome. One possible application would be for the clinician who, despite published evidence to the contrary, remains hesitant to wean in the face of favorable clinical screening criteria (adequate oxygenation, hemodynamic stability, presence of spontaneous inspiratory efforts). Only under these circumstances will weaning predictors have the potential to reduce the duration of mechanical ventilation.

\section{Competing interests}

The author declares that they have no competing interests.

\section{References}

1. Nemer SN, Barbas CSV, Caldeira JB, Cárias TC, Santos RG, Almeida LC, Azeredo LM, Noé RA, Guimaräes BS, Souza PC: A new integrative weaning index of discontinuation from mechanical ventilation. Crit Care 2009, 13:R152.

2. Meade M, Guyatt G, Cook D, Griffith L, Sinuff T, Kergl C, Mancebo J, Esteban A, Epstein S: Predicting success in weaning from mechanical ventilation. Chest 2001, 120:400S424S.

3. Yang KL, Tobin MJ: A prospective study of indexes predicting the outcome of trials of weaning from mechanical ventilation. N Engl J Med 1991, 324:1445-1450.

4. Milic-Emili J: Is weaning an art or a science? Am Rev Respir Dis 1986, 134:1107-1108.

5. Jabour ER, Rabil DM, Truwit JD, Rochester DF: Evaluation of a new weaning index based on ventilatory endurance and the efficiency of gas exchange. Am Rev Respir Dis 1991, 144:531537.

6. Maclntyre NR, Cook DJ, Ely EW, Jr., Epstein SK, Fink JB, Heffner JE, Hess D, Hubmayer RD, Scheinhorn DJ: Evidence-based guidelines for weaning and discontinuing ventilatory support: a collective task force facilitated by the American College of Chest Physicians; the American Association for Respiratory Care; and the American College of Critical Care Medicine. Chest 2001, 120:375S-395S.

7. Boles JM, Bion J, Connors A, Herridge M, Marsh B, Melot C, Pearl $\mathrm{R}$, Silverman H, Stanchina M, Vieillard-Baron A, Welte T: Weaning from mechanical ventilation. Eur Respir J 2007, 29:1033-1056.

8. Girard TD, Kress JP, Fuchs BD, Thomason JW, Schweickert WD, Pun BT, Taichman DB, Dunn JG, Pohlman AS, Kinniry PA, Jackson JC, Canonico AE, Light RW, Shintani AK, Thompson JL, Gordon SM, Hall JB, Dittus RS, Bernard GR, Ely EW: Efficacy and safety of a paired sedation and ventilator weaning protocol for mechanically ventilated patients in intensive care (Awakening and Breathing Controlled trial): a randomised controlled trial. Lancet 2008, 371:126-134.

9. Ely EW, Bennett PA, Bowton DL, Murphy SM, Florance AM, Haponik EF: Large scale implementation of a respiratory therapist-driven protocol for ventilator weaning. Am J Respir Crit Care Med 1999, 159:439-446.

10. Laghi F, Cattapan SE, Jubran A, Parthasarathy S, Warshawsky $P$, Choi YS, Tobin MJ: Is weaning failure caused by low-frequency fatigue of the diaphragm? Am J Respir Crit Care Med 2003, 167:120-127. 
11. Funk GC, Anders S, Breyer MK, Burghuber OC, Edelmann G, Heindl W, Hinterholzer G, Kohansal R, Schuster R, SchwarzmaierD'Assie A, Valentin A, Hartl S: Incidence and outcome of weaning from mechanical ventilation according to new categories. Eur Respir J 2009, doi:10.1183/09031936.00056909.

12. Tanios MA, Nevins ML, Hendra KP, Cardinal P, Allan JE, Naumova EN, Epstein SK: A randomized, controlled trial of the role of weaning predictors in clinical decision making. Crit Care Med 2006, 34:2530-2535. 